\title{
Effect of Laser Cladding Al Ni TiC Powder on Microstructure and Properties of Aluminum Alloy
}

\author{
Xiaolin Zhang*, Kemin Zhang, Jinxin Ma, Yu Wang \\ College of Materials Engineering, Shanghai University of Engineering Science, Shanghai, China \\ Email: ${ }^{* 770283141 @ q q . c o m}$
}

How to cite this paper: Zhang, X.L., Zhang, K.M., Ma, J.X. and Wang, Y. (2017) Effect of Laser Cladding Al Ni TiC Powder on Microstructure and Properties of Aluminum Alloy. Journal of Minerals and Materials Characterization and Engineering, 5, 29-38.

http://dx.doi.org/10.4236/jmmce.2017.51003

Received: November 8, 2016

Accepted: December 17, 2016

Published: December 20, 2016

Copyright $\odot 2017$ by authors and Scientific Research Publishing Inc. This work is licensed under the Creative Commons Attribution International License (CC BY 4.0).

http://creativecommons.org/licenses/by/4.0/

\begin{abstract}
In this paper, $\mathrm{Al} / \mathrm{Ni} / \mathrm{TiC}$ powders were mixed on the surface of $\mathrm{A} 380$ aluminum alloy, by selecting appropriate laser parameters; the cladding layer with good adhesion to the substrate was obtained. The microstructure and properties of the cladding layer under different laser parameters were analyzed. The results show that: the phase composition of the cladding layer is mainly composed of $\mathrm{TiC}, \mathrm{Al}, \mathrm{Ni}, \mathrm{C}$ and $\mathrm{Ti}$ phases. The hardness of the cladding region is up to $173.3 \mathrm{HV}$, which is about 2.9 times the matrix $(-59.1 \mathrm{HV})$. The corrosion voltage $(-1.8 \mathrm{~V})$ of the cladding layer shifted significantly from the corrosion potential $(-1.18 \mathrm{~V})$, the corrosion current density increased, the resistance value decreased and the diameter of the capacitor arc decreased; all these phenomena indicate that the corrosion resistance of the cladding layer is decreased.
\end{abstract}

\section{Keywords}

Aluminum Alloy, Laser Cladding, TiC Powder, Microstructure, Corrosion Resistance

\section{Introduction}

Aluminum alloys are widely used in aerospace, automotive and power machinery because of their low density, good plasticity, easy processing and low cost. But its low hardness, poor corrosion resistance, poor thermal stability and other shortcomings, limit its wider application. Casting aluminum alloy has good performance, but the manufacturing cost is high, at this stage is not conducive to the promotion of a wide range. Therefore, it is feasible to improve the surface properties of aluminum alloy by modifying the surface of aluminum alloys [1] [2]. 
Laser cladding is a method to improve the surface properties of the substrate alloy by fusing coating powders and the surface of the substrate, which enables the coating powder to be solidified on the surface of the substrate and organically combined with the substrate. Compound powder has many kinds, and the composite ceramic powder has the advantages of high strength, wear resistance, low coefficient of expansion, and so on. It has been widely studied and applied [3]. R. Anand Kumar et al. [4] mixed Al-12\% (mass fraction, the same below) $\mathrm{Si}$ alloy powder and $\mathrm{TiC}$ powder, and then clad them on the surface of $\mathrm{Al}-7 \% \mathrm{Si}$ casting alloy by Nd:YAG laser with continuous wave; the microstructure of the cladding layer was observed and analyzed, and the sliding friction and wear test were carried out in the coating with less than $5 \%$ void and no other defects. The results show that $\mathrm{TiC}$ particles, dendritic $\alpha-\mathrm{Al}$ and interdendritic $(\alpha-\mathrm{Al}+\mathrm{Si})$ eutectic and $\mathrm{Ti}_{3} \mathrm{SiC}_{2}$ are mainly distributed in the cladding layer, indicating that TiC particles are partially dissolved. The hardness of cladding layer was increased by $50 \mathrm{HV}$, analyzing that the presence of $\mathrm{TiC}$ and $\mathrm{Si}$ particles could improve the surface hardness of the matrix. The sliding friction and wear tests were carried out using $400 \mathrm{C}$ tool steel as the friction material. The results showed that the friction coefficient decreased 2 - 3 times compared with the matrix; more iron and iron oxides and a little $\mathrm{Al}$ and $\mathrm{Si}$ were found on the surface of the substrate. However, TiC particles were not found. The analysis shows that the $\mathrm{TiC}$ particles play a role in supporting the friction during the friction process, which limits the wear of the coating. Dunja Ravnikar et al. [5] pre-coated $\mathrm{TiB}_{2}-\mathrm{TiC}-\mathrm{Al}$ powder mixtures in the European standard 6082-T651 aluminum alloy surface, with $3 \mathrm{KW}$ continuous wave fiber laser multi-lap cladding treatment, and obtained less than $2 \%$ void and no other defects coating. The microstructure and the chemical properties of the coating were analyzed. The results show that there are only $\mathrm{TiB}_{2}, \mathrm{TiC}$ and $\mathrm{Al}$ phases in the cladding layer, and no new phases are formed. The average hardness of the coating is about $40 \%$ higher than that of the matrix, in $\mathrm{TiB}_{2}$, $\mathrm{TiC}$ particles where the hardness value is even more. The wear resistance test showed that the coating had much less mass loss than the matrix alloy and improved abrasion resistance by about 8 times. In addition, the presence of $\mathrm{TiB}_{2}$ and $\mathrm{TiC}$ particles improves the bending properties of the alloy surface, effectively delaying the occurrence of bending cracks. Residual compressive stresses are found in the coating enabling the coating surface to withstand greater loads and increase the life cycle to some extent.

$\mathrm{TiC}$ intermolecular bond is composed of ionic bond, covalent bond and metal bond, which has high melting point, high boiling point and high hardness, stable chemical properties, and is a good choice for improving the surface properties of aluminum alloy. At the same time, the metal $\mathrm{Ni}$ and $\mathrm{TiC}$ have similar wetting angle at high temperature, which can be used as the wetting phase, so that the $\mathrm{TiC}$ can be combined with the matrix better. In this paper, $\mathrm{Al} / \mathrm{Ni} / \mathrm{TiC}$ powder was mixed in the proportion, cladding on the surface of A380 aluminum alloy, the morphology of cladding was observed under different parameters, and the hardness and corrosion resistance of the cladding layers were tested. 


\section{Experimental}

A380 aluminum alloy is cut into $52 \mathrm{~mm} \times 38 \mathrm{~mm} \times 34 \mathrm{~mm}$ size, the surface with 800 sandpaper polished to ensure that the sample surface smooth and no oxide film. The powders were mixed by the mass ratio of $\mathrm{Al}: \mathrm{Ni}: \mathrm{TiC}=3: 1: 0.5$, mixed by ball milling for $13 \mathrm{~h}$, then connected with PVA as preconditioning agent on the surface of substrate, the thickness of powder was $0.5 \mathrm{~mm}$, the pretreatment of the substrate placed in the dryer for drying. Experimental laser cladding equipment is IPG-YLS-5000W yttrium-doped multimode fiber laser with laser beam spot diameter of $17 \mathrm{~mm}$, shielding gas of argon and flow rate of $20 \mathrm{~L} / \mathrm{min}$. The experimental laser parameters are shown in Table 1.

After laser cladding, the specimen is cut into a plurality of samples along the scanning direction, with No. 400, No. 800 and No. 1200 sandpaper for pregrinding and polishing. The microstructure and properties of modified layers were studied by XRD, SEM, micro hardness tester and electrochemical workstation, and compared with the untreated samples. Hardness of the load is $50 \mathrm{~g}$ and the loading time is $15 \mathrm{~s}$, between the spacing of $250 \mu \mathrm{m}$; corrosion electrochemical workstation is $3.5 \%$ (mass fraction) $\mathrm{NaCl}$ solution, a constant temperature of $25^{\circ} \mathrm{C}$, the system adopts saturated calomel electrode as reference electrode, platinum electrode as auxiliary electrode, the sample for 1 hours in the static medium. Until the system is stable, determinate electrochemical polarization curves, the initial potential scanning potential for $-2 \mathrm{~V}$, scan termination potential is $1 \mathrm{~V}$, the scan rate is $1 \mathrm{mV} / \mathrm{s}$. When measuring the electrochemical impedance spectrum, choose the measurement under the self-corrosion potential, the frequency range is set to $0.01-100,000 \mathrm{~Hz}$.

\section{Results and Discussion}

\subsection{XRD Analysis}

Figure 1 shows the XRD pattern of the cladding layer. From the analysis, it can be found that there is no oxide formation in the cladding layer due to argon protection during laser cladding. The $\mathrm{TiC}, \mathrm{Ti}, \mathrm{Ni}$ and $\mathrm{Al}$ phases were mainly in the upper part of the cladding layer. A small amount of pure $\mathrm{C}$ phase was also observed, and the AlNi compound and other phases were not observed. After laser cladding, $\mathrm{Ti}$ and $\mathrm{C}$ phases were formed in the cladding phase, which indicated that TiC was decomposed. A comparison of the XRD patterns of No. 1 and No. 2 revealed that No. 1 had a C phase at about 43.5 degrees. Due to slow laser scanning speed, resulting in a lot of heat during laser heating, to extend the existence of molten pool time, carbon and oxygen elements of the affinity, and the air reaction led to loss [6] [7]. In the case of $\mathrm{m}(\mathrm{Al}): \mathrm{m}(\mathrm{Ni})=3: 1$, only a very

Table 1. Laser parameters.

\begin{tabular}{ccc}
\hline Samples & Laser output power P & Scanning speed \\
\hline No. 1 & $3.5 \mathrm{~kW}$ & $2 \mathrm{~mm} / \mathrm{s}$ \\
No. 2 & $3.5 \mathrm{~kW}$ & $4 \mathrm{~mm} / \mathrm{s}$ \\
\hline
\end{tabular}




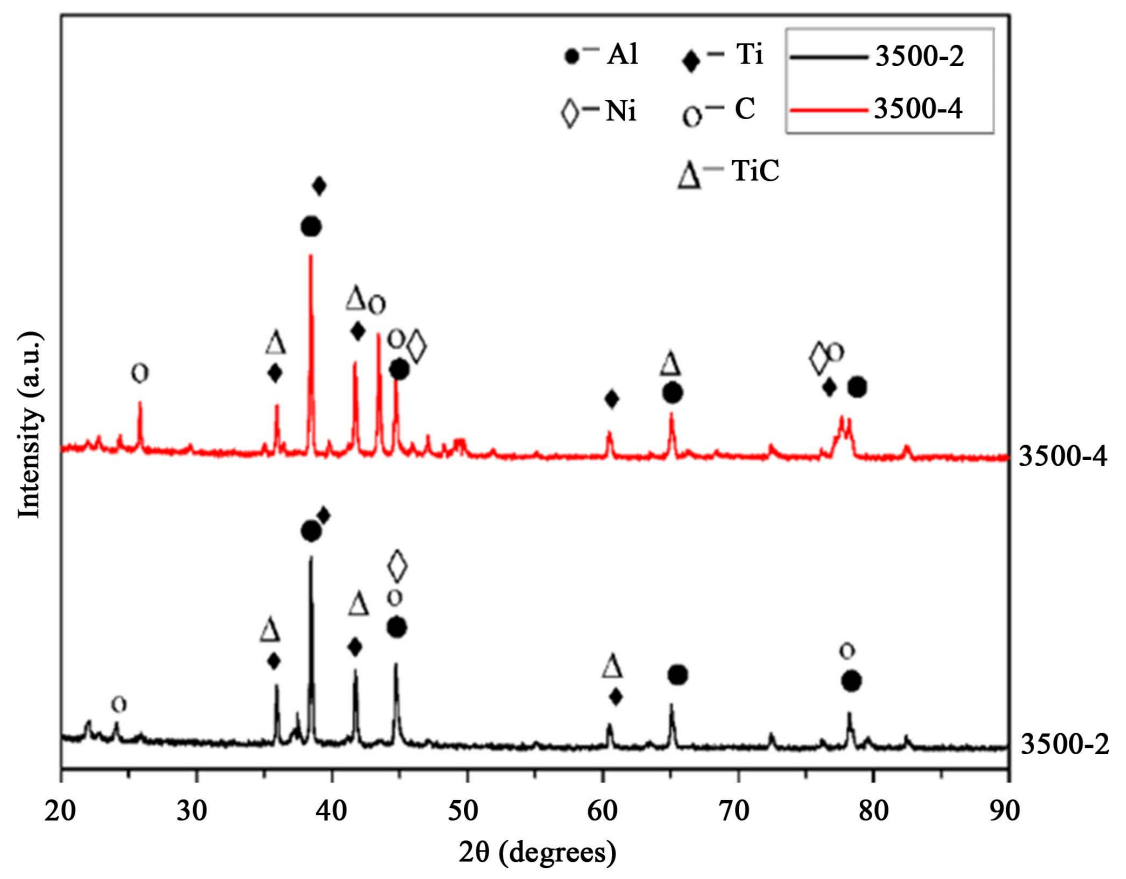

Figure 1. XRD pattern of the cladding layer.

small amount of Ni phase is observed in the cladding layer. It is believed that during the laser process, high density and melting point of $\mathrm{Ni}$ and other less intensive phase (such as $\mathrm{Al}$ ) convection, so that $\mathrm{Ni}$ deposition to the lower part of the coating [8].

\subsection{Microstructure of Surface Modification Layers}

Figure 2 for the No. 1 and No. 2 sample coating layers of scanning electron microscopy, magnification of 50 times. It can be seen from the Figure 2, TiC powder successfully laser cladding in the substrate surface. Compared with No. 2 specimen, No.1 sample cladding surface is more flat, and no bubbles and holes, the analysis of No. 2 sample at $4 \mathrm{~mm} / \mathrm{s}$ laser scanning speed, faster scanning speed lead powder cannot be completely melted, unmelted powder and matrix bonding is poor, lead the formation of holes in the bonding zone. During the cladding process, $\mathrm{Al}$ powder is thermally vaporized, and the faster scanning speed makes the vaporized $\mathrm{Al}$ less time to escape, resulting in the cladding layer of bubbles [9].

The morphology of Figure 3 as substrate microstructure magnified 1500 times, can be seen from the Figure 3, substrate consists of white block of Al-Si eutectic phase (A phase), black cell and long strip of the initial silicon phase (B phase), and primary $\alpha-\mathrm{Al}$ (C phase). Primary silicon is the first phase in the solidification process, the solid-liquid interface is relatively smooth, from the macro scale, the primary silicon is the bar and block structure, with different sizes.

Figure 4(a) and Figure 4(b) show the surface morphology of cladding layer No. 1 and No. 2 with 1500 times magnification. The microstructure of the No. 1 surface layer is a block (A phase), by energy spectrum analysis for AlNi compo- 
(a)

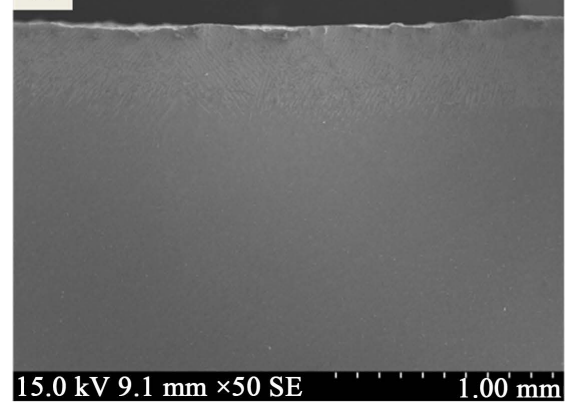

(b)

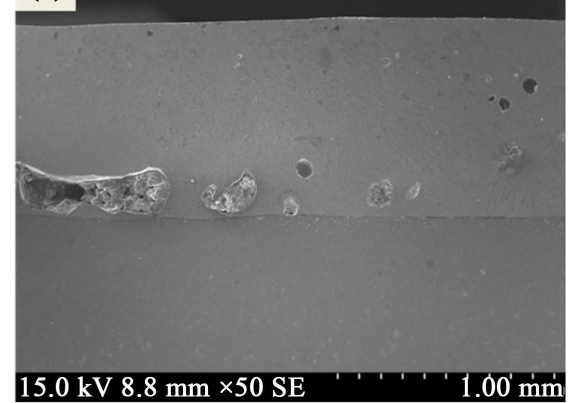

Figure 2. Coating layer of scanning electron microscopy.

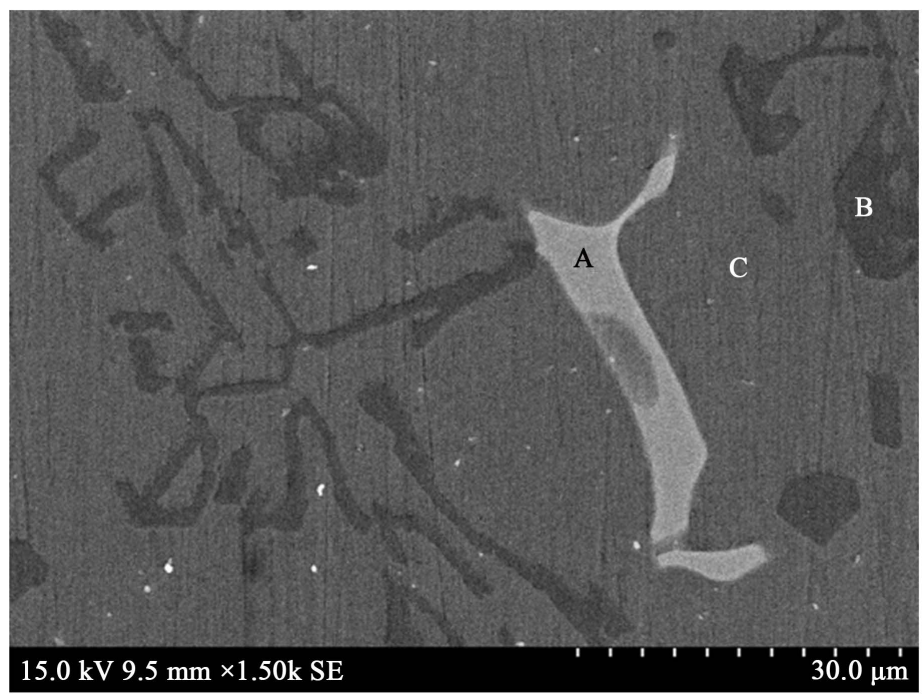

Figure 3. Microstructure of substrate.
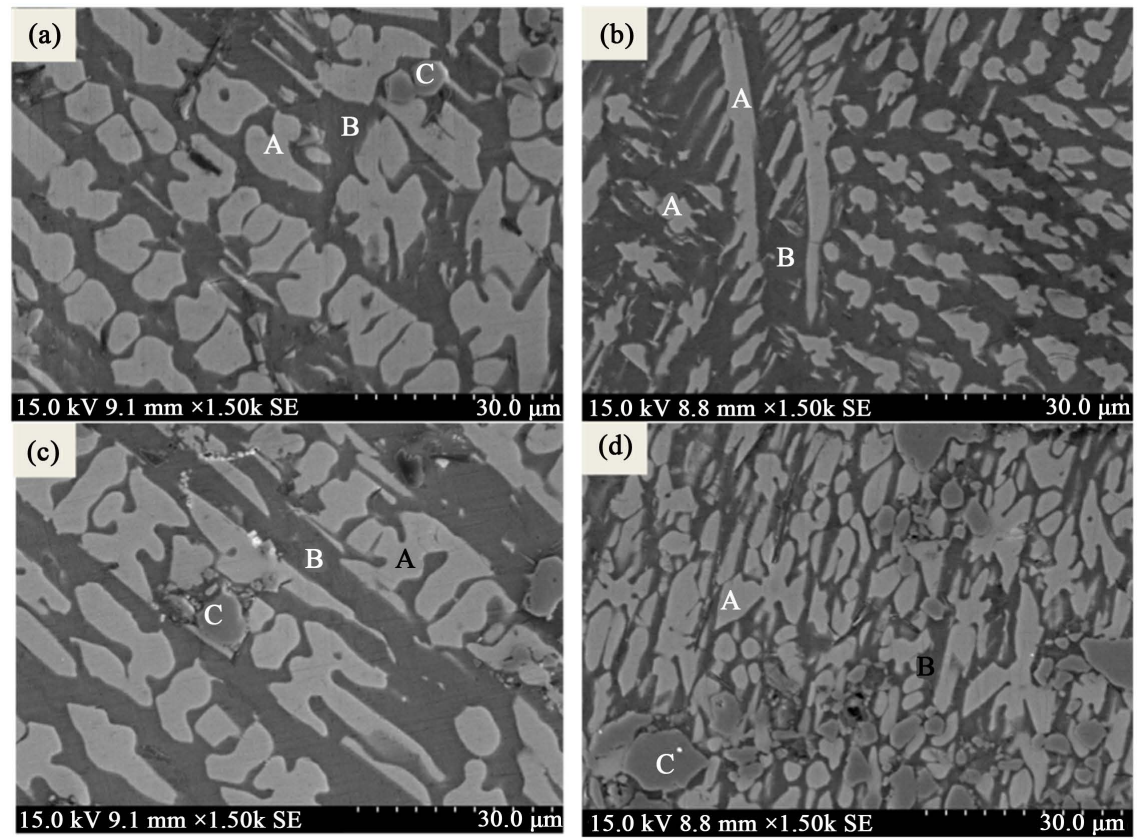

Figure 4. Morphology of the cladding layer: (a) for No. 1 surface; (b) for No. 2 surface; (c) for No. 1 middle; (d) for No. 2 middle. 
site phase, the B phase is $\alpha$ - $\mathrm{Al}$, contained a small amount of $\mathrm{Ni}$ and $\mathrm{C}$ elements, and a small amount of unmelted $\mathrm{TiC}$ particles (C phase). In addition to the massive structure (phase A), the dendritic structure of the No. 2 surface layer was observed to be the homogeneous phase, and the grain growth direction was different under the scanning speed. The results show that because the scanning speed of No. 1 is slower than that of No. 2, when the surface of the powder to be heated to above the phase transition temperature, the recrystallization process lasts for a long time, and the cooling rate is slow, aggregation and growth leading to large organizations [10].

Figure 4(c) and Figure 4(d) show the middle morphology of the cladding in the sample No. 1 and No. 2, which is 1500 times magnified by scanning electron microscopy. It can be seen from the figure that there is no obvious change in the morphology of the middle part of the specimen, and the AlNi composite phase (A phase) is still in the massive structure. Compared with the surface layer, the AlNi phase in the middle part is slightly reduced, TiC particles (C phase) increased slightly. The dendritic structure of AlNi composite phase (A phase) is thinner and denser than that of AlNi phase. The overall morphology of the AlNi composite phase is more clutter. Laser cladding process will produce a lot of heat, the surface of the cladding powder by air cooling and thermal conductivity of the substrate, can speed up the cooling rate, and the central powder in the laser heating to form the molten pool, cooling only in the form of heat conduction to the substrate heat. The cooling rate is slow, the formation of recrystallization of the organization will be coarser, and the priority in a certain direction of growth. The faster scanning speed makes the No. 2 sample in a short grain growth time, did not have time to form a more regular morphology [11].

\subsection{Hardness Analysis}

The microhardness of the laser cladding layer is shown in Figure 5. The average hardness of the cladding layer in samples No. 1 and No. 2 is $163.8 \mathrm{HV}$ and 173.3 $\mathrm{HV}$ respectively. The hardness of the cladding zone is higher than that of the substrate $(59.1 \mathrm{HV})$ nearly 3 times, and the minimum hardness of the cladding area is $89 \mathrm{HV}$. The average hardness of sample No. 2 cladding zones is greater than No. 1. Hardness of No. 1 sample cladding zone to basement area increased and then decreased. This is due to slower scanning speed, long heating time of TiC makes decomposition occurs, $\mathrm{C}$ element is exposed to the air during the cooling process, will react with oxygen and loss, leaving only the surface of $\mathrm{Ti}$, which reduces the hardness of the surface. In addition, the hardness of the cladding layer in specimen No. 1 is much higher than that of the outermost surface due to the presence of $\mathrm{TiC}$ particles in the middle part of the cladding layer. The hardness of the heat affected zone of the two specimens is higher than that of the base region, because in the cladding process, in addition to the $\mathrm{Al}, \mathrm{Ni}, \mathrm{TiC}$ powder to form the molten pool, the upper part of the matrix also melts, with the cladding bottom convection, the matrix of $\mathrm{Al}$ into the bottom of the cladding layer, diluted TiC. After rapid cooling, the upper part of the matrix is refined and the hardness is increased. 


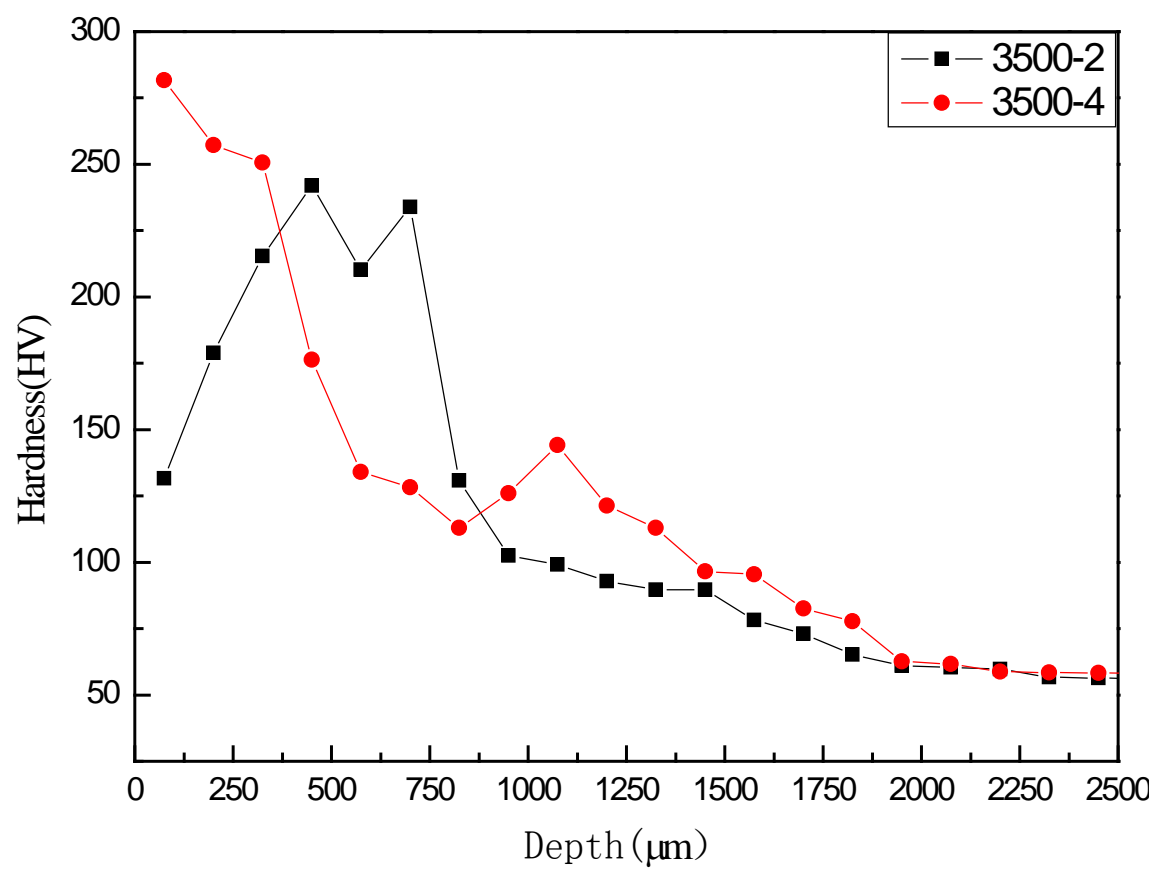

Figure 5. Microhardness of the laser cladding layer.

\subsection{Corrosion Resistance Analysis}

Figure 6 shows the Bode diagram of the samples. Figure 6(a) shows the relationship between the phase angle $\theta$ and the frequency $\mathrm{f}$, and Figure 6(b) shows the relationship between the impedance value $|\mathrm{Z}|$ and the frequency $\mathrm{f}$. In Figure 6(a), $\lg |\mathrm{Z}|$ and lgf are in a linear relationship between 1 and 10, and phase angles of No. 1 and No. 2 are significantly higher than those of the matrix. The phase angle of the substrate between 10 and $10^{2}$ is close to $80^{\circ}$, showing nearcapacitance behavior, and is higher than the phase angle of the treated sample. In addition, samples after laser cladding can show a narrower frequency range than the matrix in the near-capacitance behavior. In Figure 6(b), the cladding layer and the substrate have a rising tendency in the middle and low frequency bands, indicating that the cladding layer and the substrate surface have certain protective properties, but the cladding layer has lower impedance value than the matrix, Indicating that the corrosion rate of cladding layer is higher than that of substrate.

Figure 7 is a different pulse frequency samples of the polarization curve, analyzing the curves using the Tafel extrapolation method, can be calculated from the corrosion potential (Ecorr) and the corrosion current density (icorr), see Table 2. The self-corrosion potential of the cladding layer is higher than that of the A380 aluminum alloy matrix, and the potential of the cladding layer is shifted to the negative direction. The corrosion resistance of No. 2 sample is better than No. 1, the analysis that the C content in No. 1 slightly larger than No. 2 , reducing the density of cladding, increasing the surface of the active point, and other micro-particles constituted corrosion micro-batteries. In Figure 7, the substrate exhibits an obvious activation-deactivation transition zone, and the 


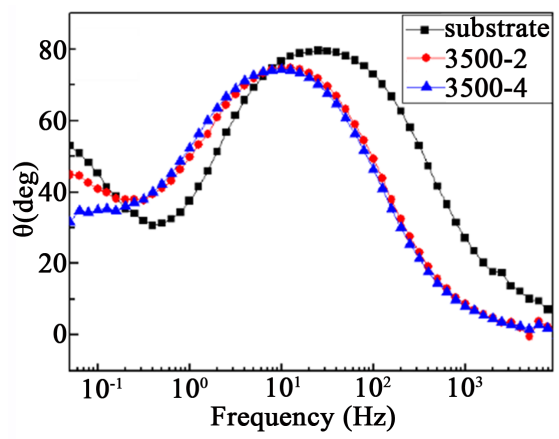

(a)

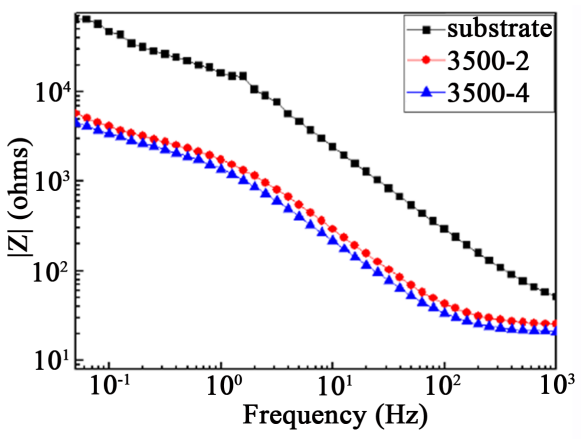

(b)

Figure 6. The Bode diagram of the sample: (a) for $f-\theta$, (b) for $f-|Z|$.

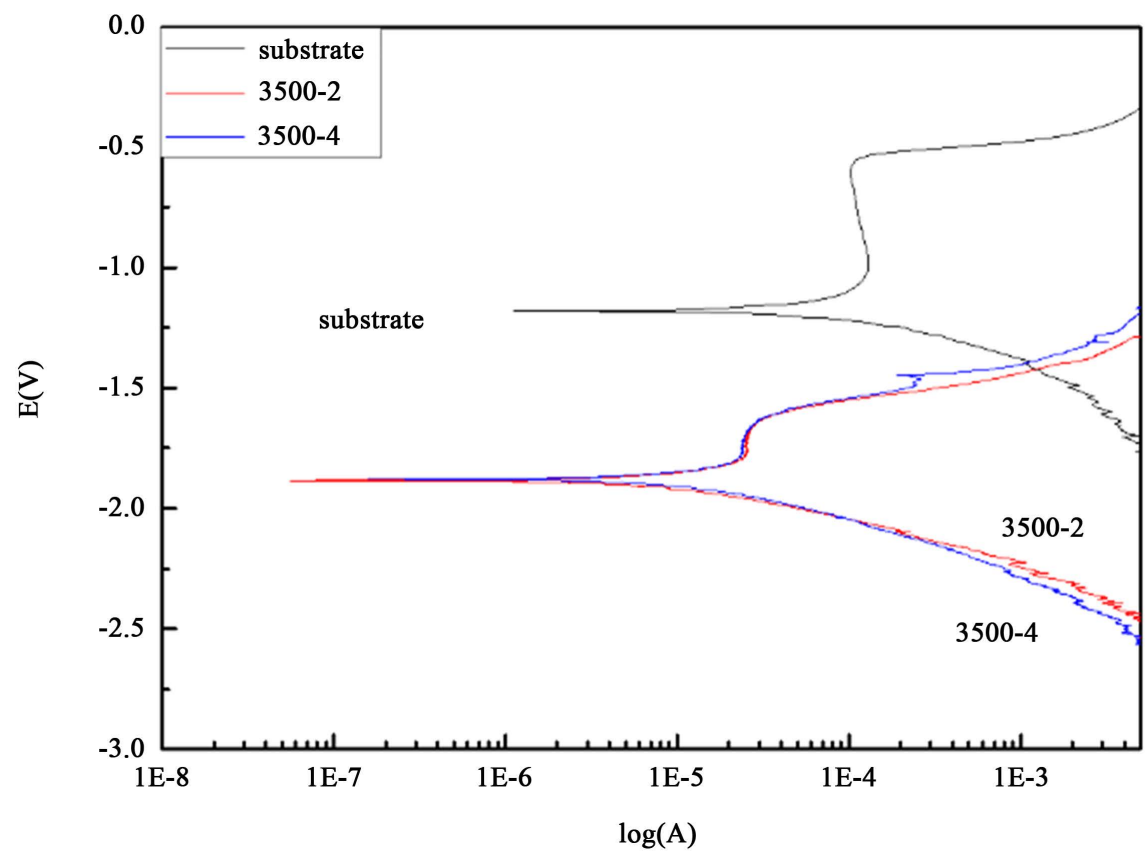

Figure 7. Polarization curve of samples.

Table 2. Corrosion date of samples.

\begin{tabular}{ccc}
\hline Samples & $\mathrm{E}(\mathrm{V})$ & $\mathrm{I}\left(\mathrm{mA} / \mathrm{cm}^{2}\right)$ \\
\hline Substrate & -1.180 & 0.05039 \\
No. 1 & -1.886 & 0.09938 \\
No. 2 & -1.878 & 0.06745 \\
\hline
\end{tabular}

passivation effect is better than that of sample No. 2 and sample No. 1 [12] [13]. The polarization potential of the substrate increases to $-0.551 \mathrm{~V}$, the polarization density of the cladding layer reaches $-0.6432 \mathrm{~V}$, the current density increases sharply, which is due to corrosion of the passive film pitting damage occurred. The pitting corrosion potential of the cladding layer is slightly lower than that of the substrate. The analysis shows that TiC particles form an interface with $\mathrm{Al}$, which is more prone to pitting corrosion. 
From the above analysis results, the corrosion resistance of the cladding layer is lower than that of the matrix, although in the laser cladding process, the convection and rapid solidification of the molten pool occur, so that the internal particles are fine and uniform, and the microstructure is uniform [14]. However, the interface of the matrix and the cladding layer are increased due to the increase of the strengthening phase, and the interface is the place where the pitting occurs. Pitting corrosion is increased and the different phase potentials of the cladding layer are different, which increases the existence of the surface active sites. The number of corrosion micro-cells increases, and the above-mentioned causes decrease the corrosion resistance of the clad layer [15].

\section{Conclusions}

We can make some conclusions from the present investigation:

1) By XRD analysis, the phase composition of the cladding layer is mainly composed of $\mathrm{TiC}, \mathrm{Al}, \mathrm{Ni}, \mathrm{C}$ and $\mathrm{Ti}$. The microstructure of the cladding layer was mainly composed of a white block (Al-based composite phase) and a small amount of $\mathrm{TiC}$ particles. The dendritic morphology of the aluminum matrix composite phase was also found due to the increase of scanning speed.

2) The average hardness of claddings in samples No. 1 and No. 2 is $163.8 \mathrm{HV}$ and $173.3 \mathrm{HV}$, which is about $2.8-2.9$ times that of substrate $(-59.1 \mathrm{HV})$, indicating that the cladding layer effectively improves the surface hardness of A380 aluminum alloy.

3) The self-corrosion voltage $(-1.8 \mathrm{~V})$ of the cladding layer shifted significantly from the corrosion potential $(-1.18 \mathrm{~V})$, the corrosion current density increased, the resistance value decreased, and the capacitance arc diameter decreased. It is believed that the increase of the strengthening phase in the cladding leads to the increase of the interface between the substrate and the cladding layer, which leads to the increase of the pitting corrosion, and the different potentials of the cladding layer increase the number of corrosion microcells and reduce the corrosion resistance of the cladding layer.

\section{References}

[1] Zubielewicz, M. and Gnot, W. (2004) Mechanisms of Non-Toxic Anticorrosive Pigments in Organic Waterborne Coatings. Progress in Organic Coatings, 49, 358371. https://doi.org/10.1016/j.porgcoat.2003.11.001

[2] Cai, X., Yang, X.Y., Chen, Q.L. and Bu, X.M. (2000) Microstructure of Laser Surface Melting (LSM) Layers on Cast Al-Si Alloy. Cailiao Gongcheng/Journal of Materials Engineering, 4, 6-10.

[3] Tomida, S., Nakata, K., Saji, S. and Kubo, T. (2001) Formation of Metal Matrix Composite Layer on Aluminum Alloy with TiC-Cu Powder by Laser Surface Alloying Process. Surface \& Coatings Technology, 142-144, 585-589. https://doi.org/10.1016/S0257-8972(01)01172-0

[4] Anandkumar, R., Almeida, A., Colaço, R., Vilar, R., Ocelik, V. and Hosson, J.T.M.D. (2007) Microstructure and Wear Studies of Laser Clad Al-Si/SiC (p) Composite Coatings. Surface \& Coatings Technology, 201, 9497-9505. https://doi.org/10.1016/j.surfcoat.2007.04.003 
[5] Ravnikar, D., Dahotre, N.B. and Grum, J. (2014) Laser Fabrication of $\mathrm{TiB}_{2} / \mathrm{TiC} / \mathrm{Al}$ on EN AW-6082-T651 Aluminium Alloy Surface. Annals of the Faculty of Engineering Hunedoara, 12, 105-110.

[6] Man, H.C., Yang, Y.Q. and Lee, W.B. (2004) Laser Induced Reaction Synthesis of $\mathrm{TiC}+$ WC Reinforced Metal Matrix Composites Coatings on Al 6061. Surface \& Coatings Technology, 185, 74-80. https://doi.org/10.1016/j.surfcoat.2003.10.132

[7] Katipelli, L.R., Agarwal, A. and Dahotre, N.B. (2000) Laser Surface Engineered TiC Coating on $6061 \mathrm{Al}$ Alloy: Microstructure and Wear. Applied Surface Science, 153, 65-78. https://doi.org/10.1016/S0169-4332(99)00368-2

[8] Cai, L.X., Wang, H.M. and Wang, C.M. (2003) Corrosion Resistance of Laser Clad Cr-Alloyed $\mathrm{Ni}_{2} \mathrm{Si} / \mathrm{NiSi}$ Intermetallic Coatings. Surface \& Coatings Technology, 176, 294-299.

[9] Ghosh, K., Mccay, M.H. and Dahotre, N.B. (1999) Formation of a Wear Resistant Surface on Al by Laser Aided In-Situ Synthesis of MoSi 2 . Journal of Materials Processing Technology, 88, 169-179. https://doi.org/10.1016/S0924-0136(98)00389-6

[10] Basavakumar, K.G., Mukunda, P.G. and Chakraborty, M. (2008) Influence of Grain Refinement and Modification on Microstructure and Mechanical Properties of Al-7Si and Al-7Si-2.5Cu Cast Alloys. Materials Characterization, 59, 283-289. https://doi.org/10.1016/j.matchar.2007.01.011

[11] Li, M.C., Jiang, L.L., Zhang, W.Q., Qian, Y.H., Luo, S.Z. and Shen, J.N. (2007) Electrodeposition of Nanocrystalline Zinc from Acidic Sulfate Solutions Containing Thiourea and Benzalacetone as Additives. Journal of Solid State Electrochemistry, 11, 549-553. https://doi.org/10.1007/s10008-006-0194-Z

[12] Kwok, C.T., Man, H.C. and Cheng, F.T. (2001) Cavitation Erosion-Corrosion Behaviour of Laser Surface Alloyed AiSi 1050 Mild Steel Using Nicrsib. Materials Science \& Engineering $A, 303,250-261$. https://doi.org/10.1016/S0921-5093(00)01850-5

[13] Singh, I.B., Mandal, D.P., Singh, M. and Das, S. (2009) Influence of SiC Particles Addition on the Corrosion Behavior of $2014 \mathrm{Al}-\mathrm{Cu}$ Alloy in 3.5\% NaCl Solution. Corrosion Science, 51, 234-241. https://doi.org/10.1016/j.corsci.2008.11.001

[14] Rosa, R.L.D., Earl, D.A. and Bierwagen, G.P. (2002) Statistical Evaluation of EIS and ENM Data Collected for Monitoring Corrosion Barrier Properties of Organic Coatings on Al-2024-T3. Corrosion Science, 44, 1607-1620. https://doi.org/10.1016/S0010-938X(01)00173-1

[15] Norlin, A., Pan, J. and Leygraf, C. (2002) Investigation of Interfacial Capacitance of $\mathrm{Pt}, \mathrm{Ti}$ and $\mathrm{TiN}$ Coated Electrodes by Electrochemical Impedance Spectroscopy. Biomolecular Engineering, 19, 67-71. https://doi.org/10.1016/S1389-0344(02)00013-8 
Submit or recommend next manuscript to SCIRP and we will provide best service for you:

Accepting pre-submission inquiries through Email, Facebook, LinkedIn, Twitter, etc. A wide selection of journals (inclusive of 9 subjects, more than 200 journals)

Providing 24-hour high-quality service

User-friendly online submission system

Fair and swift peer-review system

Efficient typesetting and proofreading procedure

Display of the result of downloads and visits, as well as the number of cited articles Maximum dissemination of your research work

Submit your manuscript at: http://papersubmission.scirp.org/

Or contact jmmce@scirp.org 